\title{
Visual Pollution in the Context of Conflicting Design Requirements
}

\author{
Sumartono \\ Design Department, Indonesia Institute of the Arts (ISI) at Yogyakarta
}

\begin{abstract}
All designs (graphic, product, and interior designs) are directed to consider certain requirements which are followed by logical thinking to fulfill a design process. Once the requirements of each design have been well-considered and the logical design process has been fulfilled, the design is complete. Ideally, all designs are not supposed to be in conflict with each other because each one is based on a logical design process. In reality, however, the mutual existence of these designs has produced conflicting requirements and thereby conflicting logics. This conflict can be seen in visual pollution. This paper will examine the impact of visual pollution caused by billboards, street signs, posters, houses/buildings, automobiles, shopfront graphic designs, packaging designs, graffiti, etc. in the context of conflicting logics/requirements. Today, opposition grows everywhere against all visually polluting designs and outdoor advertising is the most prominent one. Some people think that it should be banned from the city. Some others, however, think that if advertisements are removed from the city, it will become a bland concrete jungle. Every city in Indonesia needs a clean-city law to control illegal advertisements and signs. It is possible to make legal yet attractive advertisements that will give positive contribution to "visual democracy" in Indonesia.
\end{abstract}

Keywords: design; visual pollution.

\section{$1 \quad$ Introduction}

Recently, there is a fast-growing awareness among people in many countries, including Indonesia, of the danger of visual pollution. Combined with other pollutions such as haze and illegally-built structures erected by poor people in Indonesia, which are not the concern of this paper, it constitutes a very serious threat to human life in this country. 'Visual pollution' is a term used broadly to cover limits on the ability to view distant objects, subjective issue of visual clutter, intruding structures on beautiful scenes, and other visual defacement. This term is used specifically in this paper to cover limits on the ability to view esthetic objects in full or in proper placement. Visual pollution is also the result of design out of context with the environment or already existing elements. This part of environmental pollution is an aesthetic issue consisting of signs which do not concern us, yet impinge on our eyes. These are among others billboards, 
street signs, posters, houses/buildings, automobiles, shopfront graphic designs, packaging designs, graffiti, etc.

Most of them have been designed based on design requirements followed by logical thinking. In everyday life or in commercial sense, they have to competing each other to attract people. This has encouraged designers and companies to make attracting billboards, street signs, posters, houses/ buildings, automobiles, shopfront graphic designs, packaging designs, graffiti, etc. in various sizes. Consequently, in many parts of human environment, especially in the cities in Indonesia, it is impossible to view esthetic objects in full or in proper placement. It is very important to note that even if they are based on logical thinking, their form, sizes, and placement often conflict each other.

\section{Inevitable Logical Conflicts among Designs}

It has to be pointed out at the outset that the meaning of every word or concept is never stable, so are the words 'requirement' and 'logic.' In this paper, it is enough to say that a requirement is a thing that is required. In design context, a good set of requirements must be fulfilled to satisfy the client. It is the obligation of the designer to capture client requirements. In design context, requirements can be divided into 'functional requirements' and non-functional requirements.' The first point to what a client wants a design to function. The latter points to restriction are a design will encounter.

The term 'logic' came from the Greek word logos, which is interchangeably translated as word, sentence, reason, discourse, or rule. Due to the impossibility to grasp one stable meaning of this word, here logic is defined as the mechanism of correct reasoning principles. In design context, every designed artifact is based on design requirements followed by logical thinking.

Unlike in more exact field such as civil engineering, correct reasoning principles in design represent only one aspect of logic, which is called by Sigfried Maser [1] as the logic of the head or 'rationality.' The other aspect of logic that also has to be considered in the process of designing is the logic of the heart or 'intuition.' This logic leads to the "objective quality" of products resulted from rationally calculated length, weight, depth, sizes, etc. The logic of the heart leads to the "subjective quality" of products resulted from carefully considered feelings, emotions, fantasies, etc. In order for a design to be successful, it must be able to transform these two logics into a dialogue that will lead to the logic of life and the logic of survival. It is important to remember that these two logics do not harmonize well. It is inevitable for a design process to keep this dialogue working although in popular sense people tend to consider a design solely the work of rationality or the logic of the head. 
Some design experts point out that every good design involves a design process consisting of certain stages. This process should take into account the design requirements (functional and non-functional/restrictive) that have been negotiated by client and designer. It will become clear that number of stages varies between one design and the other. Every design process is based on the dialogue between two logics mentioned in the previous paragraph. The process is not easy as clear from the following simplified summary of the main stages in graphic, product, and interior design processes for comparison, quoted and slightly modified from David Rivett's essay entitled "Project Management". In this context, not all projects involve all stages [2]. It will become clear that although these design processes are based on the dialogue between the two logics mentioned above, the conflict of logics is always unavoidable. Design process never offers an ultimate solution. A potentially large variety of design solutions is possible to fulfill the requirements of a design. Even according to Krippendorff it is justifiable to propose that design is making sense (of things) [3]. Buchanan points out that the design eludes reduction and remains a surprisingly flexible activity [4]. It is clear from this that the meaning of design is loose. Design is inevitably concerned with dilemma situations.

\begin{tabular}{|c|c|}
\hline SHARED STAGES & PRODUCT \\
\hline 1. Review the brief & 1. Prototypes \\
\hline 2. Client familiarization & 2. Prototypes evaluation \\
\hline 3. Research & 3. Production planning \\
\hline 4. Finalize the brief & 4. Design refinement \\
\hline 5. Agree responsibilities & 5. Final presentation \\
\hline 6. Concept design & 6. Design freeze \\
\hline 7. Concept presentation/review & 7. Pre-production prototype \\
\hline 8. Agree concept(s) for development & 8. Tooling \\
\hline development/detailed & $\begin{array}{l}\text { 9. Manufacture } \\
\text { 10. Project review }\end{array}$ \\
\hline GRAPHICS & INTERIORS \\
\hline 1. Mock-up/dummies & 1. Interim presentation $/$ models \\
\hline 2. Consumer research & 2. Design refinement \\
\hline 3. Design refinement & 3. Final presentation \\
\hline 4. Final presentation & 4. Design freeze \\
\hline 5. Design freeze & 5. Working drawings \\
\hline 6. Typesetting & 6. Tendering \\
\hline 7. Artwork/photographs & 7. Shop drawings \\
\hline 8. Proofing & 8. Pilot fit-out \\
\hline 9. Paste-up & 9. Pilot evaluation \\
\hline 10. Printing/converting & 10. Further refinement \\
\hline 11. Project review & 11. Fit out \\
\hline & 12. Hand-over \\
\hline & 13. Project review \\
\hline
\end{tabular}

Figure 1 The design process - a simplified summary of the main stages; after David Rivett. 
The above list inform us that good designs must follow uneasy logical steps and they will conflict each other after functioning, no matter how logical each design seems to be or how extensive all kinds of representation formats (diagrams, sketches, drawings, layouts, etc.) have been made. The conflicting logics may not only involve the three design processes representing the three design fields but also involve stages inside each design field even without the intervention of the two others. That is why after functioning for some time there is another stage in every design called design review. It is obvious now how multidimensional the conflicting logics are. In conclusion, each design process needs not only the logic of the head/rationality but also the logic of the heart/intuition. It is important to remember that requirements analysis can be a long and arduous process and even when the unclear, incomplete, ambiguous, or contradictory stated requirements have been resolved, there is no guarantee that a design is absolutely finished.

\section{$3 \quad$ Impacts on Design-Related Daily Life}

Conflicting logics in design have serious impacts on several sectors of designrelated daily life and more specifically in the context of this writing is visual pollution. A popular example is what happens in many major cities in Indonesia where some historical buildings cannot be viewed from all sides due to the presence of one or more big billboards blocking certain view to those buildings. The proliferation of billboards in many cities in Indonesia is spurred by the growth of automobile traffic. From the perspective of historicity and design, most architects or interior designers might be of the opinion that logically all views toward those historical buildings be protected from any blocking structure. The reason is that because historical buildings were made in the past following logical requirements to be viewed from all sides and it is very important to show them to the public in full and proper placement for cultural education purpose. However, the billboard designer might think differently; he or she might have used his or her own logic to locate the billboard at that position to be noticed easily by people. Although not following all design stages mentioned by Rivett above, many designers incorporate some of them when designing a billboard. He or she thinks that the selected stages are significantly represented a design and logic.

Today big billboards, some featuring semi-naked models, dominate the views of many cities in Indonesia. As a matter of fact, these billboards may be considered as out of context with the environment. The designers who made them may be accused of failing to consider the relationship with existing components of the visual environment. In his logical context, however, there was no other choice except making big size billboards. Otherwise, people would not notice them easily and another company probably would take the 
opportunity and also made a big billboard, which would also use its own logic. Unfortunately, somehow today local governments seem to be careless. They may use their own logic not to ban them because advertisements pour a big sum of money to cities.

It is ridiculous that a number of important figures in some local governments sometimes still talk in the newspapers about the optimism to make their cities beautiful. Ironically, big billboards featuring big-size photographs of prominent governmental and political figures are scattered around Indonesian cities today. In addition, big cigarette billboards have also been continuously erected in Indonesian cities, and even villages. Cigarette billboards are truly the king of outdoor advertising world in this country. The cigarette industry is a spectacular success story, so most prominent governmental and political figures prefer to be silent concerning with the serious danger of cigarette smoking.

Recently there has been a deep concern on the blackening of rows of overpass footings in Jakarta due to weather pollution. Some urban experts suggest that utilizing the space for advertising could create a more esthetic cityscape and generate income for the city. Potential areas under Jakarta's overpasses are among others Slipi, West Jakarta, and Pademangan, North Jakarta Viewed from design perspective; nothing goes wrong with this idea. Designing advertisements on rows of overpass footings could be made logical after considering a set of requirements. But it sounds good because only functional requirements are concerned. From the perspective of non-functional requirements, however, the esthetic future seems to be unclear because not long after the completion of the advertisements, the overpass footings quite probably will be covered with flyers or posters.

Street signs are also a contributing part to visual pollution in Indonesia. In many streets in big cities like Jakarta, Surabaya, Medan, Bandung, Makassar, Semarang, and Yogyakarta, there are abundant examples of polluting street signs. They accompany the pre-existing obligatory traffic signs which are also, due to the often improper placement, already polluting streets of those cities. Small announcement sheet signs or flyers are very often stuck on electricity and property poles or surfaces of any structure. Many of the stuck sheets are not taken off even when the announcement on it has expired. Unfortunately, they will be replaced by other flyers. During campaign period of Indonesian general election conducted one month ago, various political parties stuck many small signs on electricity and property posts all over town, but until now many of them have not been taken off. Now the general election is finished and no one is responsible for the removal of the expired campaign sheets. It is wrong to think that all these stick announcement sheets are not designed. Some of them were designed to fulfill certain design requirements based on certain logic. They were 
designed to notice people walking or moving nearby, therefore their sizes and placement had already been considered.

Street views in Indonesian big cities are also densely populated by posters in various dimensions which are stick illegally on the surfaces of many public buildings and facilities. It is common that posters like this stay on the surfaces for months so that finally the cities become dirty for a long time. It is possible even to find a certain political party poster put on the outer surface of a bridge five years ago still sticking safely today, albeit it is dirty. The main reason for sticking posters on the surfaces of many public buildings and facilities is because it is free of charge yet disseminate information effectively. Poster is a popular form of graphic design. Poster design also incorporate stages of a design process. It is created based on client's set of requirements and logic. Here again we realize that the fulfillment of logical design requirements never takes into account the post-functioning of the posters. A large number of posters' pollutes views of Indonesian big cities everyday. It is impossible to clean them because posters come and go rapidly. Combined with street banners, they make those cities more visually polluted. .

When buildings are being blocked by big billboards, architects complain. In visual pollution context, however, architecture is not innocent. Some luxurious buildings have been built in this country recently. The architects who designed them might have thought that they were in context with the environment because they were built based on a set of requirements followed by logical thinking. Poor people living near those buildings today, however, may think differently. The presence of these buildings may also mean for them the presence of visual pollution since they are feeling depressed living close to money-consuming buildings. What the architects think as in-context buildings are out-of-context ones for them. A good example is the Jatim Expo Building at Ahmad Yani Street, Surabaya. With total exhibition floor of $5120 \mathrm{~m} 2$ it has been classified as international in stature. A number of prestigious events have been organized here. In extreme contrast, however, small houses of poor people living close to this building tell a different story. In front of them usually the people dry clothes in the sun. This non-functional requirement was beyond the logic of the designer to handle. It was impossibility and it is logical, depending from what logical perspective he viewed. Interior design may also cause visual pollution. It can be seen obviously from the establishment of relatively new malls in many cities in Indonesia. Ambarrukmo Plaza, in Yogyakarta, is an example. True that this mall has boosted local economy and created jobs and entrepreneurial opportunities for people in the neighborhood, but visual pollution is unavoidable. The existence of this mall has caused the establishment of small shops which sell various things. As a result, traffic congestion is unavoidable and the area becomes very crowded. This mall sells 
luxurious products, while it occupies a location where many poor families live. Although it has boosted local economy and created jobs, in a sense it has nothing to do with the poor. While they live a poor life as usual, they have to keep in touch not only with luxurious products exhibited in the interior spaces of the mall but also with those exhibited in some quality stores recently built nearby. Conflicting logics are obvious here. The design of the mall was based on a logical design process, but the non-functional requirements in the form of environmental restrictions, especially poverty, are also logical. The point is that the environmental constraint has not been overcome.

Good will on the part of a local government may also result in visual pollution. An interesting lesson can be learnt from a small apartment built by the city of Yogyakarta on the edge of Code River. Previously the apartment was built to provide poor people with a low-price apartment rooms for leasing. The set of requirements of this apartment included the ability of it to house tens of families live a normal life here. Occupants must have been expected to keep the environment clean. What we see today however is far from what has been expected. It is a daily sight that everyday most of the families hang wet clothes which are blocking good views. Although the apartment was previously intended to be built in context, today it tends to be out of context with the environment. The building becomes dirty and less attractive. Although this nonfunctional requirement might have been considered in the design process, the real world tells a different story today.

Automobiles have also been considered a factor in creating visual pollution. Automobile traffic has grown very rapidly in Indonesian big cities. Traffic in big cities like Jakarta, Surabaya, Medan, Bandung, and Makassar becomes very crowded. Here visual pollution in this sense is not the responsibility of car designers since traffic jam, as a non-functional requirement, is beyond the capability of a car designer. At least in designing a car he or she has to follow a design process stages more or less like those which have been listed above logically. It is just like the designing of Toyota Vios, as a replacement of the Toyota Soluna. The designer must have designed it as a true private car. But in Indonesia it has been used as taxicabs as well and is specially rebadged as the Toyota Limo. Beyond the previous anticipation of the designer, and it was not his or her responsibility, it has caused disappointment among buyers. For the Vios' owners the Limo is a kind of visual pollution as well.

In Jakarta bus advertisements has boosted the income of bus company owners. However, bus advertisements have been accused of contributing a lot in shaping visual pollution in Jakarta. Bus designers are not responsible for the inclusion of advertisements on the interior and exterior of buses. There is no single logic could validly ban bus advertisements. The point is that not all advertisements 
affixed to buses are well-designed and many well-designed advertisements are often dirty all time. Buses and bus advertisements also play a role in the making of visual clutter. Visual clutter can be defined as over crowdedness in a certain place, especially in a big city, where there are found not only traffic jam but also the presence of big and small street signs, billboards of various sizes, franchise architecture housing a number of branded fast food, restaurants and stores, overhead stretches of utility wires, etc. Visual clutter will disorient people who happen to be at the location. An example of visual clutter in Jakarta is the area around Roxymas. Visual clutter of this kind can be said to represent "a big conflict of design logics" because all kinds of design are involved in it. Visual clutter can be found easily in many Indonesian big cities.

Packaging design is one of the most exciting areas of design today. Packaging design has the primary goal to attract customers' attention. For this purpose, package designs can not simply inform the customers, but also provoke feelings and communicate emotions. An effective packaging looks attractive and impresses many people with its creativity. Packaging design is part of a wider combination, in which corporate identity, advertising, display, and promotion play an important part. Designing a package is not a simple matter, it also has to fulfill a set of requirements which are followed by logical thinking. A good package design is the one that logically take into account the after-usage impact of the design. Some package designs so far have fulfilled this requirement, but many others do not pay attention to this. This has resulted in the excessive amount of packages made of material which is difficult to recycle such as that aluminum foil used for sachet (a small disposable bag). Waste food containers in the form of sachet are abundant in Indonesia, not only in big but also small cities, even villages. Everyday some passengers also throw food sachets out of buses and trains passing cities and villages. It is difficult to understand that low-price chips marketed among poor people are wrapped in a fairly luxurious aluminum foil with beautiful design on the outside of the package. This "sachet culture" plays a very important part in visual pollution.

Shopfront designs also contribute a lot to the lingering visual pollution. The purpose of a shopfront is to display goods for sale and entice customers into the shop. A well-designed shopfront will create a good impression to potential customers. Unfortunately, many shopfronts in the cities in Indonesia are not well-designed, although they are attractive. They are often filled with excessive signs in the form of flat boards or individual letters. Small banners are sometimes added. The number of advertisements tends to be kept to a maximum. It is not clear whether this has something to do with the mentality of most Indonesians. Sizes, materials, and detailing of many shopfront designs even do not respect the age and character of the buildings. This defacement is common in many big cities. 
Graffiti has been a very serious, long problem in many big cities in Indonesia. Graffiti is any type of public markings scratched or painted on various surfaces, especially walls. Spray paint and markers have become the most popular materials. Sometimes graffiti is made to convey political messages or publicize the name of a youth gang. Graffiti may become a form of vandalism when it is made to deface property without the property owner's permission. In big cities, overpass footings have also been covered with graffiti as advertisements. Conflicting logics are also obvious here. In engineering or design perspective, an overpass is not supposed to be covered with any advertisement, including graffiti. It is justifiable to say that graffiti as advertisement is vandalistic and out of context with the environment if it is made on the wrong surface. But local governments might think that graffiti as advertisement is not vandalistic or out of context with the environment as long as it is artistic and generate income.

\section{Conclusion: Possible Ban of Outdoor Visual Pollution}

Visual pollution has caused people in Indonesian cities unable to view esthetic objects in full or in proper placement. Advertisements have been bitterly criticized. Out of the examples mentioned above, billboards dominate the landscape in cities, especially big cities in Indonesia. They invade citizen's privacy day and night. Meanwhile, cigarette billboards are truly the king of outdoor advertising world and probably tobacco products are the most heavily advertised type of product. Even though generally billboards in the streets of cities in this country were designed following a set of requirements and logical thinking, most billboards were made out of context with the environment or with the already existing elements.

Today opposition grows very rapidly in the world against advertising. It is the most hated of all designs. Many cities in the world have banned advertising. Since 2006 Gilberto Kassab, the mayor of Sao Paulo, Brazil's most important city, has been successful in banning outdoor advertising and becomes a hero. The news about his daring policy has spread all over the world. Prior to that year, Sao Paulo was recognized as one of the billboard and sign jungles of the world. Some people think that outdoor advertising should be banned from any city. Some other people, however, think that if advertisements are removed from a city, it will become a bland concrete jungles. I am of the opinion that not all designs, especially advertisements, are supposed to be blamed for visual pollution. Every city in Indonesia needs a clean-city law to control illegal advertisements and signs. It is possible to make legal yet attractive advertisements that will give positive contribution to "visual democracy" in Indonesia. In the case of billboards, it is advisable to relocate them in order not to block good views in many places, not only cities. 


\section{Reference}

[1] Maser, Siegfried. 1992. Product Appearance and Product Quality, in Objects and Images: Studies in Design and Advertising, ed. Susann Vihma. Helsinki: University of Industrial Arts Helsinki.

[2] Rivett, David. 1992. Project Management, in Professional Practice in Design Consultancy, ed Liz Lydiate. London: the Design Council.

[3] Krippendorff, Klaus. 1995. On the Essential Contexts of Artifacts or on the Proposition that 'Design is Making Sense (of Things), in The Idea of Design, ed. Victor Margolin and Richard Buchanan. Cambridge, Mass., and London: MIT Press.

[4] Buchanan, Richard. 1995. Wicked Problems in Design Thinking, in The Idea of Design, ed. Victor Margolin and Richard Buchanan. Cambridge, Mass., and London: MIT Press. 